\title{
Identification of dietary patterns by principal component analysis in schoolchildren in the South of Brazil and associated factors
}

Gabriela Rodrigues Bratkowski 1

D https://orcid.org/0000-0001-6170-5029

Vanessa Backes 2

iD https://orcid.org/0000-0002-3860-7866

Maria Teresa Olinto 3

https://orcid.org/0000-0002-3950-4594

Ruth Liane Henn 4

https://orcid.org/0000-0002-5056-4934

1-4 Programa de Pós-graduação em Saúde Coletiva. Universidade do Vale do Rio dos Sinos. Av Unisinos, 950. Cristo Rei. São Leopoldo, RS, Brasil. CEP: 93.022- 750. E-mail: gabriela.brat@gmail.com

\begin{abstract}
Objectives: to identify dietary patterns $(D P)$ and associated factors in first grade schoolchildren in elementary schools in the South of Brazil.

Methods: school-based cross-sectional study, with a non-probabilistic sample of 782 schoolchildren aged 6 to 8 . Food intake was assessed by a food frequency questionnaire. DP were identified using the principal component analysis and the prevalence ratios were obtained by Poisson regression with a robust variance.

Results: four DP were identified and accounted for $25.3 \%$ of the total variance: "fruit, vegetables and fish" (8.5\%), "sweets and salty snacks" (7.0\%), "dairy, ham and biscuits" (5.0\%) and "common Brazilian food" (4.8\%). After the adjustment, breakfast habit and lower frequency of meals in front of a screen increased the probability of adherence to a high consumption of DP of "fruit, vegetables and fish". The maternal schooling level was linearly and inversely associated with DP of "sweets and salty snacks" and "common Brazilian food", and positively related to the DP of "dairy, ham and biscuits". Schoolchildren with food insecurity and sufficiently active had higher probability of adherence to DP of "common Brazilian food".

Conclusions: four DP were identified and associated with food insecurity, maternal socioeconomic characteristics and schoolchildren's behavioral characteristics.
\end{abstract}

Key words Feeding behavior, Child, Principal components analysis 


\section{Introduction}

Eating habits during childhood have a significant role in growth and development. This is an important period for educational guidance, since dietary patterns begin to be established and can be maintained during adolescence and adulthood. ${ }^{1}$ In Brazil, recent data show an insufficient consumption of vegetables and its association with the increase in consumption of ultra-processed foods. ${ }^{2}$ In addition, the literature suggest that high-fat, low-fiber, highenergy-dense dietary patterns increase the risk of overweight and obesity. 3

Studies conducted in different countries, such as Mexico, ${ }^{4}$ China $^{5}$ and New Zealand, ${ }^{6}$ have described different dietary patterns in children, but there is a common presence of patterns considered unhealthy. In Brazil, recently some studies $7-10$ have investigated empirically derived dietary patterns in children of school age; however, the literature is still scarce. Most of these Brazilian studies have analyzed dietary patterns with only the families' socioeconomic level, some maternal variables, and students demographic characteristics and body mass index.7,8,10 Overall, the results indicate that dietary patterns are influenced by the socioeconomic level. Higher family income and higher maternal schooling are associated with higher consumption of healthy dietary patterns (fruit and vegetables), and the lower consumption of patterns called "snacks". 7,10 A recent study conducted in the South of Brazil found an association between dietary pattern and physical activity level. 9 However, the association between schoolchildren's dietary patterns and behavioral characteristics is, for example: breakfast habit, consumption of food in front of the screen, and physical activity level that could be more exploited.

Considering the importance of developing and maintaining healthy eating habits, the identification of dietary patterns and their determinants in children may provide information that can guide interventions and public policy in the area of food and nutrition. The present study aimed to identify dietary patterns and associated factors in first grade schoolchildren in elementary schools in São Leopoldo, RS, Brazil.

\section{Methods}

This study used the database of the project Adesão aos "10 passos da alimentação saudável para crianças"(Adherence to the "10 steps of healthy eating for kids") among the first grade schoolchildren in elementary schools in São Leopoldo, RS, a school-based cross-sectional study, conducted between May and December in 2011. São Leopoldo, with an area of $102.738 \mathrm{~km}^{2}$, is located in the region of Vale do Rio dos Sinos and integrates the metropolitan region of Porto Alegre. According to the Instituto Brasileiro de Geografia e Estatística (Brazilian Institute of Geography and Statistics), it has an estimated population of 229.678 inhabitants. Methodology details are described in Vicenzi et al. ${ }^{11}$ Briefly at the beginning of the school year all the first grade schoolchildren (2.369) were invited to participate in the study. However, only 847 students, whose mothers accepted to participate, were included. Sixteen of them were excluded for being on special diets, 18 for lack of over $30 \%$ of data in the food frequency questionnaire (FFQ), and 31 lacked of anthropometric assessment, resulting in 782 individuals. With this sample size, the study had a statistical strength of $80 \%$ to identify significant prevalence ratios of 1.4 or higher, exposures that affect $34.7 \%$ to $45.1 \%$ of the population, with a $95 \%$ confidence level. For the principal components analysis (PCA), this sample size was three times larger than the minimal number required: five observations (individuals) for each variable (food items of the FFQ) are recommended.12 In this study, 44 types of food were included in the FFQ, requiring a total of 220 individuals.

Trained undergraduate students from the health area applied a structured, standardized and precoded questionnaire for the mothers/guardians, after the pilot study. About $40 \%$ of the interviews were conducted in the schools and the other in the households, due to the mothers' low adherence.

Food consumption information was obtained using a qualitative FFQ designed considering the food groups and consumption frequency from the "Marcadores de Consumo Alimentar" (Markers of Food Consumption) form of the Brazilian "Sistema de Vigilância Alimentar e Nutricional" (Food and Nutrition Vigilance System). ${ }^{13}$ In this form, the markers are presented as food groups, but due to the difficulties of mothers/guardians in answering about combined food in the pilot study, they were separated as individual food. For example, "raw salad" and "cooked vegetables" were separated into lettuce, cabbage, tomato, cucumber, kale, pumpkin, chayote, carrot and beet. In addition, food such as rice, maize, cassava, potato, pasta, bread, cheese, meat, chicken, fish, egg, margarine, butter and powdered juice were included in the FFQ. These food are part of the local eating habits, as shown in a study on the dietary patterns of adult women in the same city. 14 The questionnaire asked about the number of days that 
the food was consumed during the week before the interview ( 0 to 7 days of week), for a total of 44 types of food (Table 1).

Demographic and socioeconomic variables included in this study were: gender (male/female); mothers/guardians' age (20-29 years; $30-39$ years and $\geq 40$ years); economy class, defined according to the Critérios de Classificação Econômica da Associação Brasileira de Empresas de Pesquisa (AE classes) (Criteria for Economic Classification of the Brazilian Association of Research Companies), and mothers/guardians' schooling level $(\leq 5 ; 6-10$ and $\geq 11$ years of schooling).

The Food Insecurity (FI) variable was measured with the Escala Brasileira de Insegurança Alimentar (Brazilian Scale of Food Insecurity), adapted and validated in Brazil in 2004.15 This scale includes questions such as concerns about lack of food, impairment of food quality, or the experience of hunger among both adults and children, in the three months prior to the interview. Negative and positive answers were scored as 0 (zero) and 1 (one) respectively, resulting in a score ranging from 0 to 15 points. The sum of the resulting scores was classified as 0 (zero) - food safety; 1 to 5 - mild FI; 6 to 10 - moderate FI; and 11 to 15 - severe FI. For association analysis, the variable FI was dichotomized as No (zero points) and Yes (1 to 15 points).

Behavioral variables analyzed were: breakfast habit (Yes/No); eating in front of the TV, video game or computer (Often; Sometimes and Never); sedentary behavior, determined by the number of hours spent watching TV, playing video game, or at the computer ( $>2$ hours/day and $\leq 2$ hours/day) ${ }^{16}$; and physical activity level, based on the number of days during the week prior to the interview in which the child performed activities such as running, cycling, jumping rope, playing soccer, or any other that made him/her sweat or breathe harder than normal (sufficient - doing these activities daily; insufficient exercises $<7$ days a week). ${ }^{16}$

The study was submitted and approved by the Research Ethics Committee of the Universidade do Vale do Rio dos Sinos (protocol number CEP 11/013). The mothers/guardians of the schoolchildren only answered the interview after reading and signing an informed consent form.

Dietary patterns were identified by PCA, an established multivariate technique to reduce food consumption data to a smaller number of underlying factors or dietary patterns. 12 Prior to conducting the PCA, the adequacy of data was evaluated based on the value of Bartlett's test of sphericity (homogeneity of variance) and Kaiser-Meyer-Olkin (KMO). Once the factors were extracted, they were rotated by an orthogonal transformation (Varimax) to achieve a more simplistic structure with greater interpretability. The number of factors (patterns) to be retained was determined by a variance graph (screen plot), eigenvalue $>1$ and the interpretability of each component. 12 Food items with absolute factor loadings $\geq 0.30$ were considered as contributing significantly to a particular factor (pattern). 12 The patterns were named according to the food items mostly loaded in each of them.

The analysis generated factor scores were

Table 1

Food included in the Food Frequency Questionnaire (FFQ). São Leopoldo, RS, Brazil, 2011.

\begin{tabular}{lcc} 
& Food included in FFQ & \\
\hline Rice & Beet & Margarine \\
Corn & Fruit & Butter \\
Cassava & Fruit salad & Fried food \\
Potato & Milk & Sweet biscuits \\
Pasta & Cheese & Cookies with filling \\
Bread & Yogurt & Crackers \\
Beans & Meat & Salty snack \\
Lettuce & Chicken & Candy \\
Cabbage & Fish & Chocolate \\
Tomato & Egg & Gum \\
Cucumber & Sausage & Lollipop \\
Kale & Baloney / Mortadella & Block of raw brown sugar \\
Pumpkin & Frankfurters & Soda \\
Chayote & Ham & Artificial juice \\
Carrot & Salami &
\end{tabular}


recorded for each participant in the study. The scores represent the sum of loads for each factor weighted by the eigenvalue of the factor and multiplied by the standardized food group intake for each individual. They represent standardized variables with mean zero and standard deviation equal to one. The scores of each pattern were categorized into quartiles. 14

In the present study, the dietary pattern was considered a dichotomous variable: the first three quartiles formed the category "low adherence" and the fourth quartile the category "high adherence", since the higher the score, the greater the adherence to the pattern. ${ }^{12}$

Poisson regression with a robust variance was used in bivariate and multivariate analyses to estimate the prevalence ratios (PR) and CI95\% for the high consumption of each pattern. Variables with a $p$ value of $<0.20$ in the bivariate analysis were included in the multivariate analysis. This analysis was conducted based on a conceptual model of determination, established a priori, with two levels: level I included demographic and socioeconomic variables (gender; mothers' age; economical level, and mothers' schooling), and level II included FI and behavioral variables (breakfast habit; meals in front of the screen; sedentary behavior and physical activity level). First-level variables were adjusted for each one and potential confounders $(p<0.20)$ were kept for the adjustment of the second level. A level of significance $<5 \%$ was adopted (all tests were twotailed). The level of significance was tested using the Wald tests for heterogeneity and linear trend.

The IBM software SPSS version 21.0 (IBM Corp., Armonk, United States) was used for the descriptive analysis and principal component analysis. The Stata version 9.0 program (Stata Corp., College Station, United States) was used to verify the association between independent variables and each dietary pattern.

\section{Results}

Most of the schoolchildren were male (52.9\%) and belonged to a $\mathrm{D}$ economic class $(59.4 \%)$. The mean age was $6.9 \pm 0.5$ years, and FI was present in $45.1 \%$ of the sample. The mothers/guardians were mostly younger than 40 years of age (77.2\%), and $39.8 \%$ of them had 6 to 10 years of schooling. Analysis on behavioral variables showed that most of the children had breakfast daily (81.2\%), had meals in front of the TV screen often or sometimes $(57.5 \%)$, were insufficiently active $(59.1 \%)$ and had a sedentary behavior (83.1\%) (Table 2).

The KMO coefficient value of 0.78 and the
Bartlett's test of sphericity with a $p$ value $<0.001$ indicated that the PCA was adequate. Four major patterns were extracted and together explained $25.3 \%$ of total variance in dietary intake. Factor loadings and the variance explained by each pattern are presented in Table 3. The first pattern, called "fruit, vegetables and fish", was composed of different vegetables, fruit, fruit salad and fish and was the most representative of food consumption of this population, accounting for $8.5 \%$ of the total variance. The second pattern, "sweets and salty snacks", was composed basically by industrialized foods such as frankfurters, biscuits, salty snacks, sweets and soda, accounting for $7 \%$ of the total variance. The third pattern was called "dairy, ham and biscuits", and the last one, composed of typically Brazilian food, for example: beans, rice, bread, margarine and others, was named "common Brazilian food". These two patterns accounted for $5 \%$ e $4.8 \%$ of the total variance, respectively.

Crude and adjusted analyses for all dietary patterns are presented in Tables 4 and 5. After the adjustment, the probability of high adherence to the pattern "fruit, vegetables and fish" was 57\% higher for schoolchildren who never had meals in front of the screen, and was 55\% higher among schoolchildren who had breakfast habit. The variables that remained significantly associated to "sweets and salty snacks" dietary pattern were maternal schooling level, meals in front of the screen and physical activity level. Thus, the probability of adherence was $68 \%$ higher in schoolchildren of mothers with $\leq 5$ years of study compared to those whose mothers had $\geq 11$ years of study; $57 \%$ higher among those who ate meals in front of the screen often in relation to those who never had this behavior, and $41 \%$ lower among schoolchildren insufficiently active compared to active children. As to the "dairy, ham and biscuits" pattern, there was a greater probability of adherence among schoolchildren of mothers with $\geq 11$ years of study $(\mathrm{PR}=$ 1.59; CI95\% = 1.05-2.43). And finally, the "common Brazilian food" pattern was more likely in schoolchildren whose mothers had lowers schooling, in schoolchildren with FI and sufficiently active.

\section{Discussion}

This study identified four dietary patterns among the schoolchildren, which explained $25.3 \%$ of the total variance in food consumption. The variables that remained significantly associated with the patterns after adjustment were maternal schooling, FI, habit of having breakfast, having meals in front of the 
Maternal, demographic, socioeconomic, behavioral and food insecurity characteristics of first grade schoolchildren, enrolled in elementary schools in São Leopoldo, RS, Brazil, 2011. ( $N=782)$

\begin{tabular}{|c|c|c|}
\hline Characteristics & $\mathbf{N}$ & $\%$ \\
\hline \multicolumn{3}{|l|}{ Gender } \\
\hline Male & 414 & 52.9 \\
\hline Female & 368 & 47.1 \\
\hline \multicolumn{3}{|c|}{ Mothers' Age (years) } \\
\hline $20-29$ & 288 & 36.8 \\
\hline $30-39$ & 316 & 40.4 \\
\hline$\geq 40$ & 178 & 22.8 \\
\hline \multicolumn{3}{|c|}{ Economical level* } \\
\hline$B$ and $C$ & 136 & 17.4 \\
\hline D & 463 & 59.4 \\
\hline $\mathrm{E}$ & 181 & 23.2 \\
\hline \multicolumn{3}{|c|}{ Mothers' schooling (years) } \\
\hline$\leq 5$ & 271 & 34.7 \\
\hline $6-10$ & 311 & 39.7 \\
\hline$\geq 11$ & 200 & 25.6 \\
\hline \multicolumn{3}{|c|}{ Food insecurity (FI) } \\
\hline Without FI & 429 & 54.9 \\
\hline With FI & 353 & 45.1 \\
\hline \multicolumn{3}{|l|}{ Breakfast habit } \\
\hline Yes & 635 & 81.2 \\
\hline No & 147 & 18.8 \\
\hline \multicolumn{3}{|c|}{ Having meals in front of the screen** } \\
\hline Often & 233 & 29.8 \\
\hline Sometimes & 216 & 27.7 \\
\hline Never & 332 & 42.5 \\
\hline \multicolumn{3}{|c|}{ Physical activity level } \\
\hline Sufficient & 320 & 40.9 \\
\hline Insufficient & 462 & 59.1 \\
\hline \multicolumn{3}{|c|}{ Sedentary behavior (hour) } \\
\hline$>2$ & 650 & 83.1 \\
\hline$\leq 2$ & 132 & 16.9 \\
\hline
\end{tabular}

* Two missing data for this variable $(n=780)$; ** One missing data for this variable $(N=781)$.

screen and physical activity level. The explained variance of $25.3 \%$ observed is consistent with other studies which identified three to four dietary patterns in children and adolescents. ${ }^{17,18}$

Healthy dietary patterns consisting basically of fruit and vegetables, as well as unhealthy patterns usually including processed, industrialized food, were also found in other studies conducted with children, both in Brazil 8,10 and as in other countries.6,19

The presence of unhealthy dietary patterns in children could explain the current rise in obesity and the cardiometabolic risk in this population. $5,8,18$ These data indicate the importance of a permanent promotion of healthy eating, particularly in the school environment.

In relation to the "common Brazilian food" pattern, a survey conducted with children in Pelotas, RS (Brazil) identified a pattern very similar to this one, called "traditional".7 In both studies, the patterns included rice, beans, margarine and bread. These results indicate that the combination "rice and beans" is still part of the Brazilian food culture, despite changes in the dietary patterns characterized by the growing consumption of ultra-processed and industrialized food. 20

Another objective of this work was to identify factors associated with high consumption of each dietary pattern. This purpose was based on evidence 
Table 3

Factorial loads* of food according to dietary patterns observed in first grade schoolchildren enrolled in elementary schools in São Leopoldo, RS, Brazil, 2011. ( $n=782)$

\begin{tabular}{|c|c|c|c|c|}
\hline \multirow[t]{2}{*}{ Food* } & \multicolumn{4}{|c|}{ Dietary pattern } \\
\hline & egetables and fish" & "sweets and salty snacks" & "dairy, ham and biscuits" & "common Brazilian food" \\
\hline Kale & 0.639 & -0.002 & 0.054 & 0.004 \\
\hline Carrot & 0.611 & -0.115 & 0.143 & 0.042 \\
\hline Cabbage & 0.575 & 0.180 & -0.134 & 0.261 \\
\hline Beet & 0.545 & -0.003 & 0.042 & 0.034 \\
\hline Pumpkin & 0.532 & 0.020 & 0.093 & -0.036 \\
\hline Lettuce & 0.497 & -0.043 & 0.028 & 0.287 \\
\hline Tomato & 0.452 & 0.004 & 0.059 & 0.302 \\
\hline Cassava & 0.423 & 0.019 & 0.021 & 0.162 \\
\hline Potato & 0.414 & 0.216 & 0.216 & 0.127 \\
\hline Chayote & 0.408 & -0.023 & 0.107 & 0.003 \\
\hline Fish & 0.400 & 0.115 & 0.065 & -0.049 \\
\hline Cucumber & 0.390 & 0.168 & 0.009 & -0.048 \\
\hline Fruit salad & 0.375 & 0.140 & 0.094 & 0.031 \\
\hline Fruit & 0.355 & -0.049 & 0.268 & 0.296 \\
\hline Corn & 0.304 & 0.041 & 0.133 & -0.106 \\
\hline Lollipop & 0.068 & 0.666 & -0.143 & 0.030 \\
\hline Candy & 0.065 & 0.658 & -0.240 & 0.053 \\
\hline Salty snacks & -0.112 & 0.605 & 0.060 & 0.122 \\
\hline Gum & 0.103 & 0.600 & -0.181 & 0.111 \\
\hline Soda & -0.169 & 0.481 & 0.272 & -0.073 \\
\hline Cookies with filling & -0.072 & 0.408 & 0.359 & 0.080 \\
\hline Block of raw brown sugar & 0.106 & 0.387 & 0.052 & -0.014 \\
\hline Chocolate & 0.092 & 0.377 & 0.122 & -0.301 \\
\hline Frankfurters & 0.144 & 0.374 & 0.244 & -0.056 \\
\hline Fried foods & 0.081 & 0.310 & 0.199 & -0.023 \\
\hline Cheese & 0.140 & -0.104 & 0.594 & 0.042 \\
\hline Yogurt & 0.066 & 0.139 & 0.523 & 0.068 \\
\hline Ham & 0.068 & -0.048 & 0.484 & -0.023 \\
\hline Crackers & 0.289 & -0.020 & 0.364 & -0.034 \\
\hline Milk & 0.163 & -0.110 & 0.208 & -0.035 \\
\hline Margarine & 0.051 & 0.029 & 0.089 & 0.562 \\
\hline Bread & -0.022 & -0.031 & 0.057 & 0.525 \\
\hline Beans & 0.152 & -0.028 & -0.104 & 0.495 \\
\hline Rice & 0.064 & -0.057 & -0.060 & 0.471 \\
\hline Baloney / Mortadella & -0.032 & 0.254 & 0.274 & 0.409 \\
\hline Artificial juice & -0.014 & 0.075 & 0.136 & 0.377 \\
\hline Chicken & 0.080 & 0.083 & 0.042 & 0.330 \\
\hline Pasta & 0.080 & 0.244 & 0.216 & 0.027 \\
\hline Butter & 0.280 & 0.070 & 0.115 & 0.078 \\
\hline Meat & 0.053 & 0.055 & 0.243 & 0.081 \\
\hline Egg & 0.129 & 0.294 & 0.201 & 0.099 \\
\hline Salami & 0.149 & 0.106 & 0.249 & -0.011 \\
\hline Sausage & 0.040 & 0.225 & 0.279 & 0.219 \\
\hline Variance explained (\%) & 8.5 & 7.0 & 5.0 & 4.8 \\
\hline
\end{tabular}

*Factorial loads $\geq 0.30$ are in bold. 
Crude and adjusted Prevalence Ratios (PR) of high intake of dietary patterns "Fruit, vegetables and fish" and "Sweets/ salty snacks", according to socioeconomic and behavioral variables of the first grade schoolchildren enrolled in elementary schools in São Leopoldo, RS, Brazil, 2011. ( $\mathrm{N}=782)$

\begin{tabular}{|c|c|c|c|c|}
\hline \multirow[t]{2}{*}{ Variables } & \multicolumn{2}{|c|}{ "Fruit, vegetables and fish" } & \multicolumn{2}{|c|}{ "Sweets/ salty snacks" } \\
\hline & $\begin{array}{l}\text { Crude PR } \\
(\mathrm{Cl} 95 \%)\end{array}$ & $\begin{array}{l}\text { Adjusted PR } \\
(\mathrm{Cl} 95 \%)\end{array}$ & $\begin{array}{c}\text { Crude PR } \\
(\mathrm{Cl} 95 \%)\end{array}$ & $\begin{array}{l}\text { Adjusted PR } \\
(\mathrm{Cl} 95 \%)\end{array}$ \\
\hline \multicolumn{5}{|l|}{ Level I } \\
\hline Gender & $0.058 *$ & $0.068 *$ & $0.544 *$ & - \\
\hline Male & 1 & 1 & $0.92(0.69-1.21)$ & \\
\hline Female & $1.31(0.99-1.74)$ & $1.30(0.98-1.72)$ & 1 & \\
\hline Mothers' age (years) & $0.819 * *$ & - & 0.666 ** & - \\
\hline $20-29$ & 1 & & $1.05(0.73-1.51)$ & \\
\hline $30-39$ & $1.00(0.73-1.38)$ & & $0.87(0.60-1.26)$ & \\
\hline$\geq 40$ & $1.05(0.72-1.52)$ & & 1 & \\
\hline Economical level & $0.040 * *$ & $0.109 * *$ & $0.018 * *$ & $0.229 * *$ \\
\hline$E$ & 1 & 1 & $1.77(1.11-2.83)$ & $1.36(0.81-2.28)$ \\
\hline $\mathrm{D}$ & $1.38(0.94-2.02)$ & $1.38(0.92-2.05)$ & $1.30(0.85-2.01)$ & $1.13(0.72-1.77)$ \\
\hline$B$ and $C$ & $1.60(1.02-2.53)$ & $1.51(0.91-2.50)$ & 1 & 1 \\
\hline Mothers' schooling (years) & $0.145 * *$ & $0.630 * *$ & $0.002 * *$ & $0.020 * *$ \\
\hline$\leq 5$ & 1 & 1 & $1.88(1.26-2.81)$ & $1.68(1.08-2.62)$ \\
\hline $6-10$ & $1.12(0.80-1.57)$ & $1.02(0.72-1.44)$ & $1.52(1.01-2.28)$ & $1.43(0.93-2.18)$ \\
\hline$\geq 11$ & $1.05(0.91-1.88)$ & $1.10(0.74-1.65)$ & 1 & 1 \\
\hline \multicolumn{5}{|l|}{ Level II } \\
\hline $\mathrm{FI}$ & 0.771 * & - & $0.010 *$ & $0.057^{*}$ \\
\hline With FI & 1 & & $1.45(1.09-1.92)$ & $1.32(0.99-1.77)$ \\
\hline Without FI & $1.04(0.79-1.38)$ & & 1 & 1 \\
\hline Breakfast & $0.052 *$ & $0.038 *$ & $0.179 *$ & $0.064 *$ \\
\hline No & 1 & 1 & $1.26(0.90-1.76)$ & $1.38(0.98-1.93)$ \\
\hline Yes & $1.50(1.00-2.27)$ & $1.55(1.02-2.34)$ & 1 & 1 \\
\hline Meals in front of the screen & $0.013 * *$ & $0.015 * *$ & $0.011 * *$ & $0.015 * *$ \\
\hline Often & 1 & 1 & $1.61(1.17-2.22)$ & $1.57(1.14-2.17)$ \\
\hline Sometimes & $1.46(0.98-2.18)$ & $1.38(0.92-2.05)$ & $0.99(0.68-1.44)$ & $1.00(0.69-1.46)$ \\
\hline Never & $1.60(1.12-2.31)$ & $1.57(1.09-2.26)$ & 1 & 1 \\
\hline PA level & $0.181 *$ & $0.181 *$ & $<0.001 *$ & $<0.001 *$ \\
\hline Insufficient & 1 & 1 & $0.59(0.45-0.79)$ & $0.59(0.44-0.78)$ \\
\hline Sufficient & $1.21(0.91-1.61)$ & $1.21(0.91-1.61)$ & 1 & 1 \\
\hline Sedentary behavior (hour) & $0.557^{*}$ & & $0.455^{*}$ & \\
\hline$>2$ & 1 & - & $1.16(0.78-1.72)$ & - \\
\hline$\leq 2$ & $0.90(0.61-1.32)$ & & 1 & \\
\hline
\end{tabular}

$\mathrm{FI}=$ Food Insecurity; PA = Physical Activity; Level I= demographic and socioeconomic variables (gender; mothers' age; economical level; mothers' schooling; FI); Level II= Level I + behavioral variables (breakfast habit; meals in front of the screen; sedentary behavior and physical activity level); * Wald test for heterogeneity; ** Wald test for linear trend. 
Table 5

Crude and adjusted Prevalence Ratios (PR) of high intake of dietary patterns "Dairy, ham and biscuits" and "common Brazilian food", according to socioeconomic and behavioral variables of the first grade schoolchildren enrolled in elementary schools in São Leopoldo, RS, Brazil, 2011. $(\mathrm{N}=782)$

\begin{tabular}{|c|c|c|c|c|}
\hline \multirow[t]{2}{*}{ Variables } & \multicolumn{2}{|c|}{ "Dairy, ham and biscuits" } & \multicolumn{2}{|c|}{ "Common Brazilian food" } \\
\hline & $\begin{array}{l}\text { Crude PR } \\
(\mathrm{Cl} 95 \%)\end{array}$ & $\begin{array}{l}\text { Adjusted PR } \\
(\mathrm{Cl} 95 \%)\end{array}$ & $\begin{array}{l}\text { Crude PR } \\
(\mathrm{Cl} 95 \%)\end{array}$ & $\begin{array}{l}\text { Adjusted PR } \\
(\mathrm{Cl} 95 \%)\end{array}$ \\
\hline \multicolumn{5}{|l|}{ Level I } \\
\hline Gender & $0.209 *$ & - & $0.859 *$ & - \\
\hline Male & $1.20(0.90-1.59)$ & & 1 & \\
\hline Female & 1 & & $1.03(0.77-1.36)$ & \\
\hline Mothers' age (years) & $0.027 * *$ & $0.057 * *$ & $0.201 * *$ & - \\
\hline $20-29$ & $1.55(1.04-2.30)$ & $1.42(0.94-2.15)$ & $1.25(0.86-1.83)$ & \\
\hline $30-39$ & $1.26(0.84-1.89)$ & $1.19(0.79-1.79)$ & $1.04(0.71-1.53)$ & \\
\hline$\geq 40$ & 1 & 1 & 1 & \\
\hline Economical level & $0.108 * *$ & $0.522 * *$ & $0.046 * *$ & $0.318 * *$ \\
\hline $\mathrm{E}$ & 1 & 1 & $1.61(1.03-2.50)$ & $1.29(0.79-2.11)$ \\
\hline $\mathrm{D}$ & $1.43(0.98-2.08)$ & $1.24(0.83-1.85)$ & $1.04(0.69-1.58)$ & $0.93(0.60-1.43)$ \\
\hline$B$ and $C$ & $1.45(0.91-2.31)$ & $1.19(0.71-1.99)$ & 1 & 1 \\
\hline Mothers' schooling (years) & $0.002 * *$ & $0.030 * *$ & $0.009 * *$ & $0.048 * *$ \\
\hline$\leq 5$ & 1 & 1 & $1.72(1.17-2.54)$ & $1.53(0.99-2.37)$ \\
\hline $6-10$ & $1.51(1.06-2.15)$ & $1.33(0.91-1.94)$ & $1.34(0.90-1.99)$ & $1.29(0.85-1.95)$ \\
\hline$\geq 11$ & $1.81(1.24-2.63)$ & $1.59(1.05-2.43)$ & 1 & 1 \\
\hline \multicolumn{5}{|l|}{ Level II } \\
\hline $\mathrm{FI}$ & $0.044^{*}$ & $0.149 *$ & $0.002 *$ & $0.013^{*}$ \\
\hline With FI & 1 & 1 & $1.57(1.19-2.09)$ & $1.44(1.08-1.93)$ \\
\hline Without FI & $1.35(1.01-1.80)$ & $1.24(0.92-1.67)$ & 1 & 1 \\
\hline Breakfast & $0.627^{*}$ & - & $0.162^{*}$ & $0.302 *$ \\
\hline No & 1 & & 1 & 1 \\
\hline Yes & $1.10(0.76-1.59)$ & & $1.33(0.89-1.97)$ & $1.23(0.83-1.83)$ \\
\hline Meals in front of the screen & $0.913 * *$ & - & $0.296 * *$ & - \\
\hline Often & 1 & & 1 & \\
\hline Sometimes & $1.04(0.72-1.51)$ & & $0.89(0.60-1.31)$ & \\
\hline Never & $1.02(0.73-1.43)$ & & $1.17(0.84-1.62)$ & \\
\hline PA level & $0.449 *$ & - & $0.008 *$ & $0.010 *$ \\
\hline Insufficient & $0.90(0.68-1.19)$ & & 1 & 1 \\
\hline Sufficient & 1 & & $1.46(1.10-1.93)$ & $1.45(1.09-1.92)$ \\
\hline Sedentary behavior (hour) & $0.060 *$ & $0.155^{*}$ & $0.556^{*}$ & - \\
\hline$>2$ & $1.52(0.98-2.35)$ & $1.38(0.89-2.13)$ & 1 & \\
\hline$\leq 2$ & 1 & 1 & $1.11(0.78-1.60)$ & \\
\hline
\end{tabular}

FI = Food Insecurity; PA = Physical Activity; Level I= demographic and socioeconomic variables (gender; mothers' ages; economical level; mothers' schooling; FI); Level II= Level I + behavioral variables (breakfast habit; meals in front of the screen; sedentary behavior and physical activity level); * Wald test for heterogeneity; ** Wald test for linear trend.

about the influence in cultural, social, economic and lifestyle factors in the determination and characterization of eating habits. 4

Lower maternal schooling was associated with the pattern "sweets and salty snacks". This finding is consistent with the literature showing that lower maternal schooling levels may be a risk factor for unhealthy dietary patterns. ${ }^{4}$ Both the higher probability of consumption of the "dairy, ham and biscuits" pattern, and the lower probability of consumption of the "common Brazilian food" pattern among children with more educated mothers 
could be explained by the cost of food composing these patterns, since the level of schooling is indicative of the economic level in families. Furthermore, greater maternal schooling would imply the acquisition of more expensive food, and less schooling would be related with cheaper foods such as "dairy, ham and biscuits" and "common Brazilian food" patterns, respectively. ${ }^{21}$ In addition, higher schooling results in more information, which can increase the ability of healthier food choices and decrease the vulnerability of advertising influences. 22

The variable FI was related only with the "common Brazilian food" pattern, so greater adherence to this pattern was more probable among children with FI. Families in this condition present higher economic vulnerability 23 and in consequence consume cheaper food, which are included in this pattern. Investigations of the daily food consumption profile of Brazilian families affected by FI found a lower consumption of more expensive food such as meat, milk and dairy products, fruit and vegetables. 24 This pattern was more pronounced in the cases of moderate and severe FI, suggesting that this condition is an important determinant of dietary pattern.

The association found between having breakfast with the dietary pattern "fruit, vegetables and fish" shows that this habit is a positive contribution to the schoolchildren's nutrition. As one of the three main daily meals, eating breakfast is adequate and associated with healthy food intake. 25

The low frequency of meals in front of the screen was associated with high adherence of the "fruit, vegetables and fish" pattern and a protective factor for high consumption of the "sweets and salty snacks", consistent with both national26 and international27 literature reports. Television advertising of high-fat foods and sweets is reaching excessive levels. That kind of publicity affects children's food choices, as observed in a study with schoolchildren that showed an association between being attracted to a product advertised and its acquisition. ${ }^{27}$ This evidence reinforces the importance of stimulating the habit of having meals at the table, next to family members, a practice that can build healthier dietary patterns during life. ${ }^{28}$ In addition, the quantity of a food product consumed in front of the screen may not be fully acknowledged, leading to excessive intake and consequently to a higher probability of overweight. ${ }^{29}$ According to the new food guide for the Brazilian population, the habit of eating regularly and attentive, in appropriate environments and in company of friends or family, stimulates healthy dietary patterns. 22
The physical activity level variable was associated only with the "sweets and salty snacks" and "common Brazilian food" dietary patterns. The relationship between the "sweets and salty snacks" pattern and physical activity level were not in the expected direction, since it was believed that insufficiently active schoolchildren would follow this dietary pattern. The literature has shown that adolescents with inadequate consumption of fruit and vegetables are more likely to be insufficiently active when compared to adolescents with a more frequent consumption of these food, concluding that healthy habits, such as adequate consumption of fruit and vegetables and being physically active are associated. ${ }^{30}$ It is important to emphasis that the information on the schoolchildren practicing physical activity were provided by their mothers, who could have overestimated the level of activity for their children.

Some limitations of this study should be considered. It was not possible to investigate all the schoolchildren enrolled in the first grade at elementary public schools as planned. A comparison of the schools participating or not in the study showed a small but statistically significant difference on the students' average age ( $6.9 \pm 0.5$ years vs. $6.7 \pm 0,4$ years); and a higher proportion of boys among the schoolchildren included in the study $(52.9 \%)$ than in the remaining ones $(49.1 \%)$. Although the differences between the groups are not of great magnitude, it is possible that other dietary patterns could be identified among the non-studied schoolchildren, so that we cannot rule out selection bias.

Another limitation concerns the method of assessment of food intake, which was based on an instrument used by the nutritional surveillance system. Although food had been added to the original instrument list, it is possible that the FFQ did not address some of the food normally consumed by schoolchildren. This could be the reason for the low variance explained by the patterns. Recall errors in relation to information about dietary intake and the children's physical activity, provided by mothers/guardians, can also be considered a limitation in our study. However, children in the age group studied ( 6 to 8 years old) still have no capacity to answer a dietary survey and report on structured physical activities. The assessment of food consumption is a complex task, with many interfering factors that make it difficult to obtain data from an individual's intake, especially when using a proxy informant. Another aspect that should be taken into account when analyzing the results of this study is the nature of the principal component analysis. In 
this kind of analysis, the researcher makes decisions such as defining which variables will enter the analysis, the number of factors to consider, and what kind of method of rotation to use. The arbitrary nature of these decisions could affect the reproducibility of the dietary patterns found in the present study in other contexts. Finally, the cross-sectional design is another limitation, since it does not allow the establishment of temporality between exposure and outcome, despite allowing the study of association.

Despite these limitations, this study has important strengths that should be considered. Firstly, we highlight the identification of dietary patterns, through PCA, in an age group that studies this approach, are scarce in Brazil. Second, dietary patterns may better express diet complexity and this could be more relevant to food choices than approaches based on isolated food and / or nutrients.

Finally, association of eating patterns in sociodemographic and behavioral characteristics help to define health promotion policies and contribute to a better understanding in the relation between diet and risk of disease.

\section{References}

1. Movassagh EZ, Baxter-Jones ADG, Kontulainen S, Whiting SJ, Vatanparast H. Tracking Dietary Patterns over 20 Years from Childhood through Adolescence into Young Adulthood: The Saskatchewan Pediatric Bone Mineral Accrual Study. Nutrients. 2017; 9: 990.

2. Canella DS, Louzada MLC, Claro RM, Costa JC, Bandoni DH, Levy RB, Martins APB. Consumo de hortaliças e sua relação com os alimentos ultraprocessados no Brasil. Rev Saúde Pública. 2018; 52: 50.

3. Kumar S, Kelly AS. Review of Childhood Obesity: From Epidemiology, Etiology, and Comorbidities to Clinical Assessment and Treatment. Mayo Clin Proc. 2017; 92 (2): 251-65.

4. Galvan-Portillo M, Sánchez E, Cárdenas-Cárdenas LM, Karam R, Claudio L, Cruz M, Burguete-García A. Dietary patterns in Mexican children and adolescents: Characterization and relation with socioeconomic and home environment factors. Appetite. 2018; 121: 275-84.

5. Zhen S, Ma Y, Zhao Z, Yang X, Wen D. Dietary pattern is associated with obesity in Chinese children and adolescents: data from China Health and Nutrition Survey (CHNS). Nutr J. 2018; 17 (1): 68

6. Saeedi P, Black KE, Haszard JJ, Skeaff S, Stoner L, Davidson B, Harrex HA, Meredith-Jones K, Quigg R, Wong JE, Skidmore PML. Dietary Patterns, Cardiorespiratory and Muscular Fitness in 9-11-Year-Old Children from Dunedin, New Zealand. Nutrients. 2018; 10 (7): 887 .
This study identified four dietary patterns in the sample and showed that socioeconomic aspects and behavioral factors are distinctly associated with each pattern. Considering the complexity involved in determining eating habits, more studies with different approaches are needed to elucidate the relation between each pattern and the characteristics of the study population.

\section{Authors' contribuition}

Bratkowski GR and Henn RL were responsible for the study design, data analysis and interpretation and writing of the manuscript. Backes V and Olinto MT contributed to the writing of the manuscript, analysis and interpretation of the data and revised the manuscript. All authors approved the final version of the manuscript.

7. Souza RLV, Madruga SW, Gigante DP, Santos IS, Barros AJD, Assunção MCF. Padrões alimentares e fatores associados entre crianças de um a seis anos de um município do Sul do Brasil. Cad Saúde Pública. 2013; 29 (12): 2416-26.

8. Santos NHA, Fiaccone RL, Barreto ML, Silva LA, Silva RCR. Association between eating patterns and body mass index in a sample of children and adolescents in Northeastern Brazil. Cad Saúde Pública. 2014; 30 (10): 2235-45.

9. Lobo AS, Assis, MAA, Leal DB, Borgatto AF, Vieira FK, Pietro PF, et al. Empirically derived dietary patterns through latent profile analysis among Brazilian children and adolescents from Southern Brazil, 2013-2015. PLoS ONE. 2019; 14 (1): e0210425.

10. Santos LP, Assunção MCF, Matijasevich A, Santos IS, Barros AJD. Dietary intake patterns of children aged 6 years and their association with socioeconomic and demographic characteristics, early feeding practices and body mass index. BMC Public Health. 2016; 16: 1055.

11 Vicenzi K, Henn RL, Weber AP, Backes V, Paniz VMV, Donatti T, Olinto MTA. Insegurança alimentar e excesso de peso em escolares do primeiro ano do Ensino Fundamental da rede municipal de São Leopoldo, Rio Grande do Sul, Brasil. Cad Saúde Pública. 2015; 31 (5): 1084-94.

12. Hair Jr. JF, Black WC, Babin BJ, Anderson RE, Tatham RL. Análise multivariada de dados. 6 ed. Porto Alegre: Bookman; 2009. 
13. Brasil. Ministério da Saúde (MS). Protocolos do Sistema de Vigilância Alimentar e Nutricional - SISVAN na assistência à saúde. Brasília, DF; 2008.

14. Alves ALS, Olinto MTA, Costa JSD, Bairros FS, Balbinotti MAA. Padrões alimentares de mulheres adultas residentes em área urbana no Sul do Brasil. Rev Saúde Pública. 2006; 40 (5): 865-73.

15. Segall-Corrêa AM, Marin-Leon L. A Segurança Alimentar no Brasil Proposição e Usos da Escala Brasileira de Medida da Insegurança Alimentar (EBIA) 2003 a 2009. Segur Aliment Nutr. 2009; 16 (2): 1-19.

16. Anderson SE, Economos CD, Must A. Active play and screen time in US children aged 4 to 11 years in relation to sociodemographic and weight status characteristics: a nationally representative cross-sectional analysis. BMC Public Health. 2008; 8: 366.

17. Vieira DAS, Castro MA, Fisberg M, Fisberg RM. Nutritional quality of dietary patterns of children: are there differences inside and outside school?. J Pediatr. 2017; 93 (1): 47-57.

18. Zhang J, Wang H, Wang Y, Xue H, Wang Z, Du W, Su C, Zhang J, Jiang H, Zhai F, Zhang B. Dietary patterns and their associations with childhood obesity in China. Br J Nutr. 2015; 113 (12): 1978-84

19. Pérez-Rodrigo C, Gil A, González-Gross M, Ortega RM, Serra-Majem L, Varela-Moreiras G, Aranceta-Bartrina J. Clustering of Dietary Patterns, Lifestyles, and Overweight among Spanish Children and Adolescents in the ANIBES Study. Nutrients. 2016; 8 (1): 11

20 Bielemann RM, Motta JVS, Minten GC, Horta BL, Gigante DP. Consumo de alimentos ultraprocessados e impacto na dieta de adultos jovens. Rev Saúde Pública. 2015; 49: 28.

21. Darmon N, Drewnowski A. Does social class predict diet quality? Am J Clin Nutr. 2008; 87 (5): 1107-17.

22. Brasil. Ministério da Saúde. Coordenação Geral da Política de Alimentação e Nutrição. Guia alimentar para a população brasileira. 2 ed. Brasília, DF; 2014.
23. Facchini LA, Nunes BP, Motta JVS, Tomasi E, Silva SM, Thumé E, Silveira DS, Siqueira FV, Dilélio AS, Saes MO, Miranda VIA, Volz PM, Osório A, Fassa AG. Insegurança alimentar no Nordeste e Sul do Brasil: magnitude, fatores associados e padrões de renda per capita para redução das iniquidades. Cad Saúde Pública. 2014; 30 (1): 161-74.

24. Morais DC, Dutra LV, Franceschini SCC, Priore SE. Insegurança alimentar e indicadores antropométricos, dietéticos e sociais em estudos brasileiros: uma revisão sistemática. Ciênc Saúde Coletiva. 2014; 19 (5): 1475-88.

25. Afeiche MC, Taillie LS, Hopkins S, Eldridge AL, Popkin BM. Breakfast Dietary Patterns among Mexican Children Are Related to Total-Day Diet Quality. J Nutr. 2017; 147 (3): 404-12.

26. Oliveira JS, Barufaldi LA, Abreu GA, Leal VS, Brunken GS, Vasconcelos SML, Santos MM, Bloch KV. ERICA: use of screens and consumption of meals and snacks by Brazilian adolescents. Rev Saúde Pública. 2016; 50 (Suppl. 1): $7 \mathrm{~s}$.

27. Emond JA, Bernhardt AM, Gilbert-Diamond D, Li Z, Sargent JD. Commercial TV exposure, fast-food toy collecting and family visits to fast food restaurants among families living in rural communities. J Pediatr. 2016; 168: 158-63.

28. Tosatti AM, Ribeiro LW, Machado RHV, Maximino P, Bozzini AB, Ramos CC, Fisberg M. Does family mealtime have a protective effect on obesity and good eating habits in young people? A 2000-2016 review. Rev Bras Saúde Mater Infant. 2017; 17 (3): 425-34.

29. Kneipp C, Habitzreuter F, Mezadri T, Höfelmann DA. Excesso de peso e variáveis associadas em escolares de Itajaí, Santa Catarina, Brasil. Ciênc Saúde Coletiva. 2015; 20 (8): 2411-22.

30. Sharma B, Chavez RC, Nam EW. Prevalence and correlates of insufficient physical activity in school adolescents in Peru. Rev Saúde Pública. 2018; 52: 51.

Received on January 10, 2019

Final version presented on September 24, 2019

Approved on May 21, 2020 